\title{
Y-Ba-Cu-O Film Deposition by Metal Organic Chemical Vapor Deposition on Buffered Metal Substrates
}

\author{
V. Selvamanickarn, G. Galinski, J. DeFrank, C. Traurwein, and P. Haldar \\ Intermagnetics General Corporation, NY 12110, U. S. A. \\ U. Balachandran, M. Lanagan, and M. Chudzik \\ Argonne National Lab, II, 60439, U, S. A.
}

\begin{abstract}
YBa}_{2} \mathrm{Cu}_{3} \mathrm{O}_{2}$ (YBCO) nims have been deposited on buffered metal substrates by Metal Organic Chemical Vapor Deposition (MOCVD). Cuba-textured nickel substrates were fabricated by a thermomechnnienl process. Epitnxinl $\mathrm{CeO}_{2}$ fims were deposited on these substrntes by thormal evaporation. Nickel alloy substrates with biaxitally-textured Yttria-Stabilized Zirconia (YSZ) buffer layers deposited by Ion Beam Assisted Deposition were also prepared. Highly binxially-textured YBCO films were deposited by MOCVD on botb types of metal substrates. A critical current density greater than $10^{4} \mathrm{~A} / \mathrm{cm}^{2}$ at $77 \mathrm{~K}$ hns been nchieved in YBCO films on metnl substrntes.
\end{abstract}

\section{INTRODUCTION}

The newest type of HTS conductor that is being developed at Intermagnetics is surface-coated YBCO conductor. YBCO offers advantages of operation at substantially higher magnetic fields especially at temperatures above $40 \mathrm{~K}$ compared to Bi-based conductors. A 10 to 100-fold improvement in performance over Bi-based conductor has been demonstrated in short samples of YBCO tape [I]-[4]. Current densities of $1 \mathrm{MA} / \mathrm{cm}^{2}$ have been demonstrated by several groups in YBCO films deposited by Pulsed Laser Deposition (PLD) on buffered nickel-based substrates. In this work, a deposition technique that is more viable for largescale manufacturing than PLD-namely Metal Organic Chemical Vapor Deposition (MOCVD)-was developed for deposition of YBCO films on nickel-based substrates. MOCVD is used in several industries for uniform coatings of various materials on large-area substrates. Two types of metal substrates were used in this work : biaxially-textured nickel substrates with an epitaxially grown buffer layer, and nickel alloy substrates with a biaxially-textured buffer layer deposited by Ion Boam Assisted Deposition (IBAD).

\section{CUBE-TEXTURED METAL SUBSTRATES}

A cube-texturing technique was developed for fabrication of highly biaxially-textured nickel and copper substrates [5]. In this technique, metal rods are rolled and heat treated to form a flexible metal tape. Deformation and heat treatment conditions were developed to achieve a high degree of biaxial texture in the metal substrates. Fig. 1 shows $X$-ray Diffraction (XRD) theta-2theta scan and polefigure of (111) peak of a $\mathrm{Ni}$ substrate. A strong degree of (200) texturing as well as a

Manuscript reccived September 14, 1998.

This work was party supported by Department of Enerby, Air Force Ontee of Sctentific Resentrch \& New York State Encrgy Research and Development Authority good in-plane texturing is seen. The spread in the in-plane texture is typically about $10^{\circ} \mathrm{FWHM}$. Essentially, polycrystalline metal substrates with a "pseudo-single-crystal' type texture were fabricated.

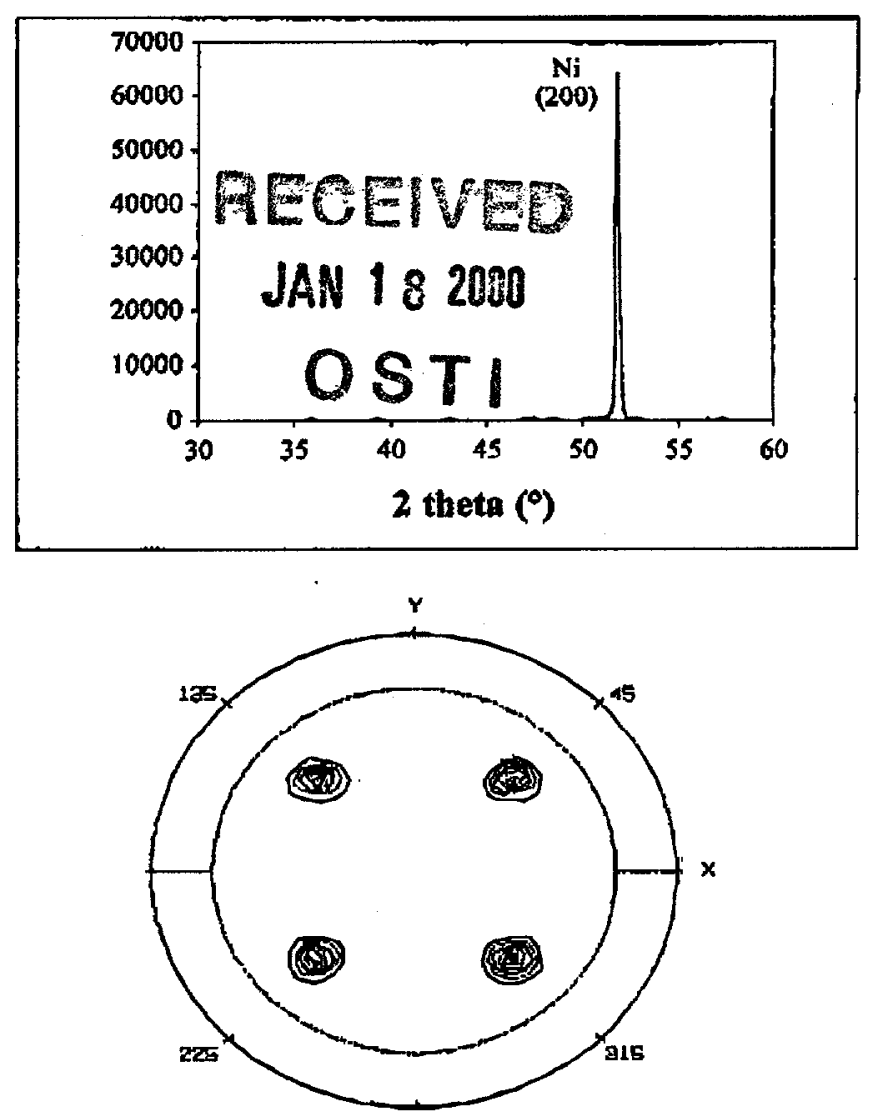

Fig. I $X$-say thetn-2theta scans and (11t) poleflgure of a blaxially-textured nickel substrate fabricated by themomechanteal processing.

A polishing process has been developed to achieve a very smooth metal substrates. Results from surface roughness mensurements by Atomic Force Microscopy (AFM) on polished, textured $\mathrm{Ni}$ samples over a relatively large area of $100 \mu \mathrm{m} \times 100 \mu \mathrm{m}$ indicate a very small RMS roughness of $1.4 \mathrm{~nm}$.

The subrultted manuacript taas been created The subriltted manuacripi has beencerator of by the University of Chicago de Operalor at Argonne National Leboratory ("Arganno") under Contract No. W-31-108-ENG-38 with the U.S. Depertment of Energy. The U.S. the U.S. Department of Ene ayd othurs andGovernment retairs for itgeli, and olhers ening on its behult, a psid-idp, nonsxclusive, Irrevoceble woxidwide llcense in' sald arlcle to repioduce. prepare dorivative works, distribute copies to the public, and pertorm put licly and display publicly. by or on beliaft of the Government. 


\section{DISCLAIMER}

This report was prepared as an account of work sponsored by an agency of the United States Government. Neither the United States Government nor any agency thereof, nor any of their employees, make any warranty, express or implied, or assumes any legal liability or responsibility for the accuracy, completeness, or usefulness of any information, apparatus, product, or process disclosed, or represents that its use would not infringe privately owned rights. Reference herein to any specific commercial product, process, or service by trade name, trademark, manufacturer, or otherwise does not necessarily constitute or imply its endorsement, recommendation, or favoring by the United States Government or any agency thereof. The views and opinions of authors expressed herein do not necessarily state or reflect those of the United States Government or any agency thereof. 


\section{DISCLAIMER}

Portions of this document may be illegible in electronic image products. Images are produced from the best available original document. 


\section{BUFFER DEPOSITION BY THERMAL EVAPORATION}

Next, a thermal evaporation process was developed to deposit buffer layers such as $\mathrm{CeO}_{2}$ on biaxially-textured nickel substrates. In this process, $\mathrm{Ce}$ or other metals are thermally evaporated and the vapor is condensed on biaxially-textured metal substrases held at a high temperature. Deposition conditions such as temperature, deposition rate, chamber pressure, and gas flow rate were optimized to achieve epitaxial growth of highly biexially-textured $\mathrm{CeO}_{2}$ buffer layers on Ni substrates. $\mathrm{CeO}_{2}$ films with a spread in the in-plane texture as low as $5^{\circ}$ FWHM as well as (200) texnure almost as intense as that of the nickel substrate were fabricated. Fig. 2 shows XRD theta-2theta scan and polefigure of (ill) peak of a $\mathrm{CeO}_{2}$ layer on a Ni substrate. $\mathrm{A}$ strong degree of (200) texturing as well as good in-plane texturing can be seen in the figure. A high degree of biaxialtexture has been achieved over a wide range of film thickness $\left(500\right.$ to $5000 \mathrm{~A}^{\circ}$ ).
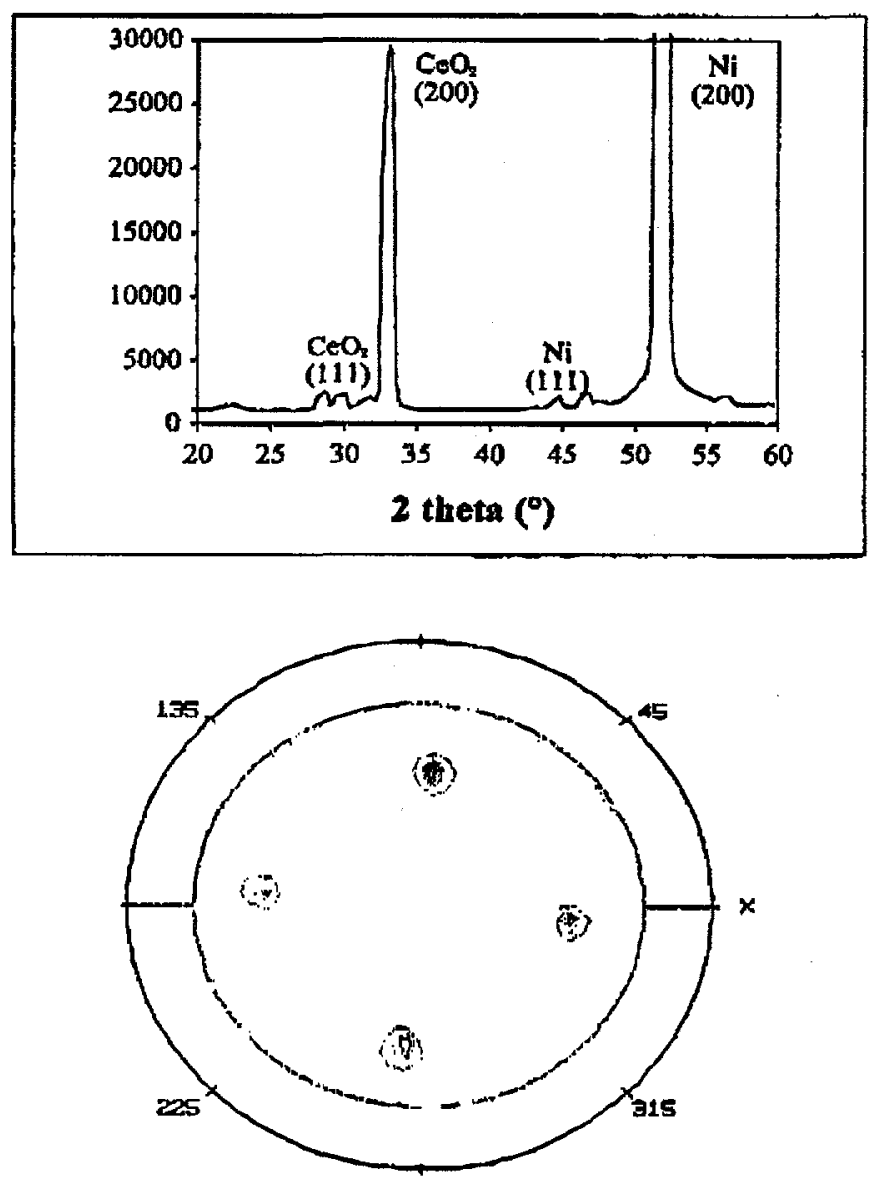

Fig. $2 \mathrm{X}$-riy thetg-2theta scans and (1II) polefigure of a $\mathrm{CeO}_{2}$ buffer film deposibed on a biaxially-kextured nickel substrate by thermal evaporation

\section{BIAXIALLY-TEXTURED BUFFER LAYERS BY IBAD}

The second type of metal substrate that was used in this work was untexnured Hastelloy C substrate. Yttria-stabilized zirconia buffer layers were deposited by ion-beam-assisted electron beam evaporation on unpolished Hastelloy $C$ substrates to a film thickness of $0.65 \mu \mathrm{m}$ [6]. A $300 \mathrm{eV}$ assisting ion beam of $\mathrm{Ar} / 10 \% \mathrm{O}_{2}$ was incident on the substrate during film growth at an angle of $35^{\circ}$ with respect to the substrate surface using an 8-cm Kaufinan-type DC ion source. The atomic deposition rates were $1.6 \mathrm{~A} / \mathrm{s}$ and the ion flux was $200 \mu \mathrm{A} / \mathrm{cm}^{2}$ to yield an ion-to-atom flux ratio of 2.8 . Fig. 3 shows a X-ray phi-scan of a YSZ film deposited on a Hastelloy substrate. Evidence of in-plane texture is observed, although it is broad compared to the $\mathrm{CeO}_{\mathrm{z}}$ buffer layer on biaxially-textured nickel substrate described in fig. 2 .

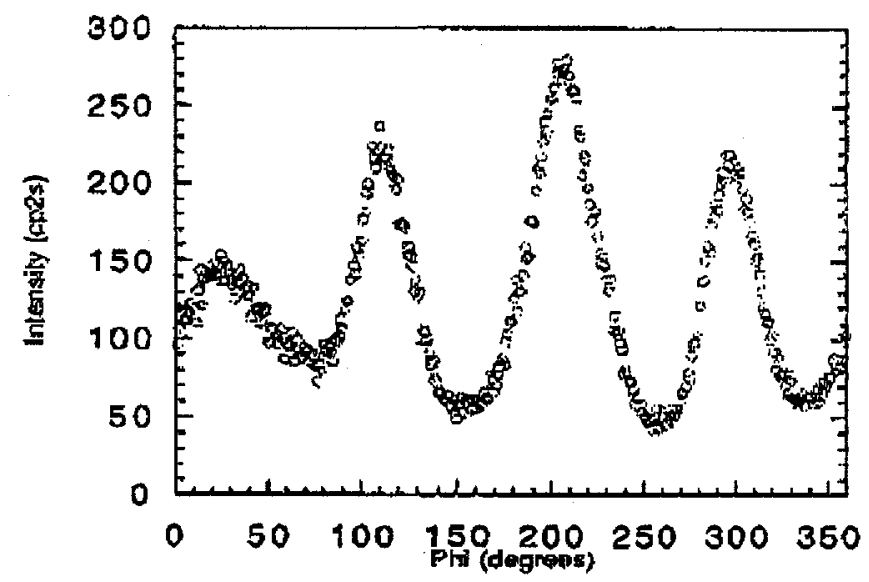

Fig. 3 X-ray pht-scan obtained from a YSZ film deposited by IBAD on an untextured Hastelloy substrate. Biaxial cexturing of the buffer layer can be seen

\section{IV, YBCO DEPOSITION BY MOCVD}

An industrial type MOCVD facility was construeted at Intermagnetics for YBCO deposition on buffered biaxially textured metal substrates. In a MOCVD process, metal organies of each of $\mathrm{Y}, \mathrm{Ba}$, and $\mathrm{Cu}$ are individually sublimed, and the vapors are transported in a carrier gas such as Ar. The vapors are then mixed with oxidents such as $\mathrm{O}_{2}$ and $\mathrm{N}_{2} \mathrm{O}$ and the mixture is decomposed just above a heated substrate to yield a YBCO film. Deposition parameters such as the deposition temperature, reactor pressure, oxidant partial pressure, carrier gas flow rates, and precursor sublimation temperanures determine film features such as film morphology, uniformity, thickness, particle formation, texture, composition as well as film properties such as transition temperature and critical current density. Tailoring of the deposition process to a specific microstructure and property is possible by a proper choice of individual process variables.

The MOCVD process was first optimized for YBCO deposition on unbuffered single crystal substrates of YtriaStabilized Zirconia (YSZ) which is one of the most common buffer materials used with YBCO conductor. Critical currents 
in excess of $20 \mathrm{~A}$ were consistently achieved in YBCO films by optimizing the deposition process to fabricate very uniform, smooth, continuous films with no visible gradients in thickness. Also, second phase particles were reduced substintially and compositions close to stoichiometric were achieved. Fig. 4 shows a microstructure of one such YBCO film. The film is seen to be uniform with few second phase particles.

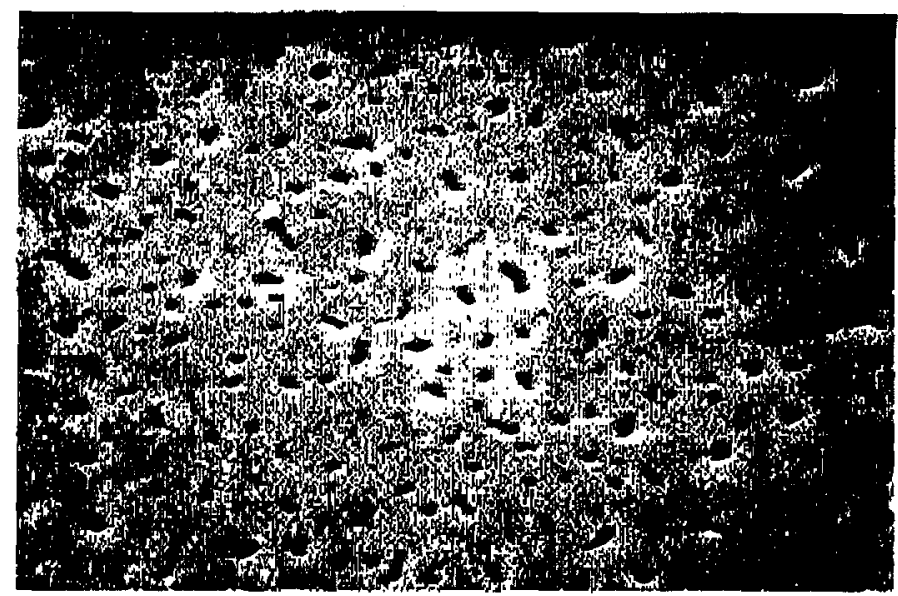

Fig. 4 Mierostructure of a YBCO film deposited by MOCVD on single crystalline YSZ substrate after process optimizention. The film is uniform with very few second phase particles.

Critical currents in excess of $40 \mathrm{~A}\left(J_{0}\right.$ of about $\left.1 \mathrm{MA} / \mathrm{cm}^{2}\right)$ have been achieved in YBCO films deposited on unbuffered, single crystalline YSZ substrates. A I-V curve obtained from one such film is shown in fig. 5. The measurement was conducted on a film area of $1 \mathrm{~cm} \times 0.4 \mu \mathrm{m}$. No transition was observed up to 38 A when the film and substrate cracked. The cracking of the film and the substrate is believed to be due to heating at the current contacts in the absence of a silver overlayer on the YBCO film.

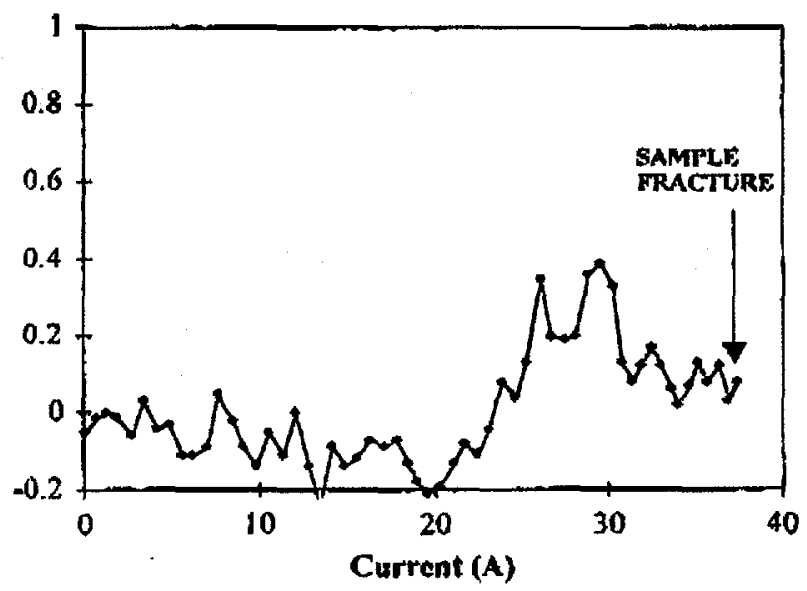

Fig. 5 Cursent-vohtage curve obtained from YBCO film deposited by MOCVD on a single erystal unbuffered YSZ substrate. The sample fractured at 38 A before trangition from superconducting state.
The performance of the YBCO film shown in fig. $S$ is impressive considering that the lattice mismatch between YBCO and YSZ is about $5 \%$. Typically, critical current density of $1 \mathrm{MA} / \mathrm{cm}^{2}$ is achieved usually in YBCO deposited on single crystal substrates of $\mathrm{SrTiO}_{3}$ or $\mathrm{LaAlO}_{3}$ where the lattice mismatch is abour $0.2 \%$. The achievement of high current as well as a high $J_{5}$ in YBCO deposited on single crystal YSZ is very encouraging for our efforts for YBCO deposition on metal substrates.

Results from YBCO films on buffered, biaxially-textured metal substrates are also promising. Fig. 6 shows XRD theta2theta scan and polefigure of (113) peak of a YBCO film on a $\mathrm{CeO}_{2}$ buffered Ni substrate. The XRD measurements were obtained from the entire sample surface. A strong degree of c-axis texturing as well as a good in-plane texturing can be seen in the figure.
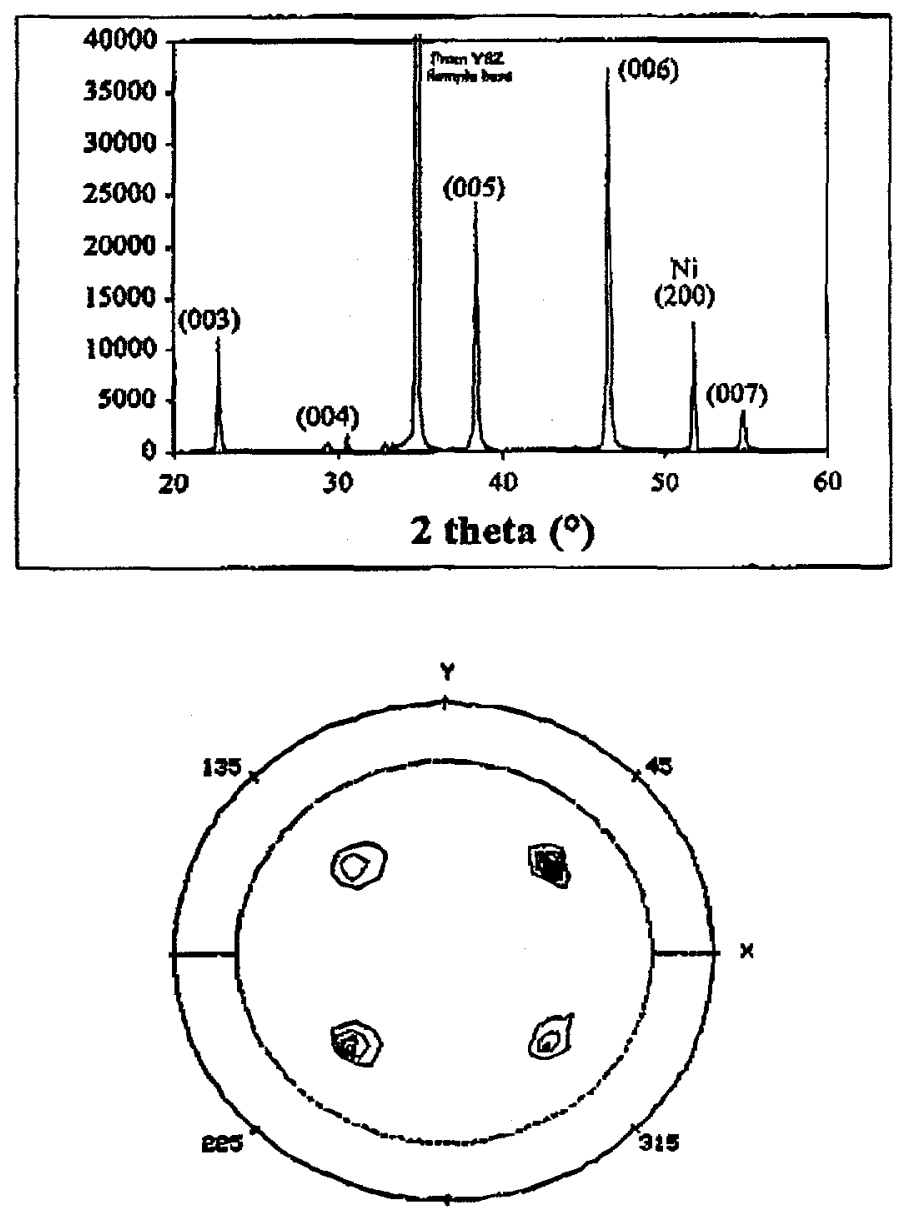

Fig. 6 X-ray theta-2theta and (1 13) polefigure obtained from a YBCO alm deposited by MOCVD on a CeO,-buffered nickel substrnse. $A$ high degree of biaxlal texture can be seen. The YSZ peak is from a single crystal YSZ bese that was used to support the sample.

Good c-axis texture and in-plane texture were also achieved in YBCO films deposited on IBAD YSS buffered 
Hastelloy substrates. The YBCO films were however rough because the YSZ layer was deposited on unpolished metal substrates. In spite of the roughness and the very broad texture of the YSZ buffer layer, a good $T_{0}$ (onset of $92 \mathrm{~K}$ and $T_{\mathrm{c}, \mathrm{n}, \mathrm{m}}$ of $87 \mathrm{~K}$ ) was achieved as shown in fig. 7. The

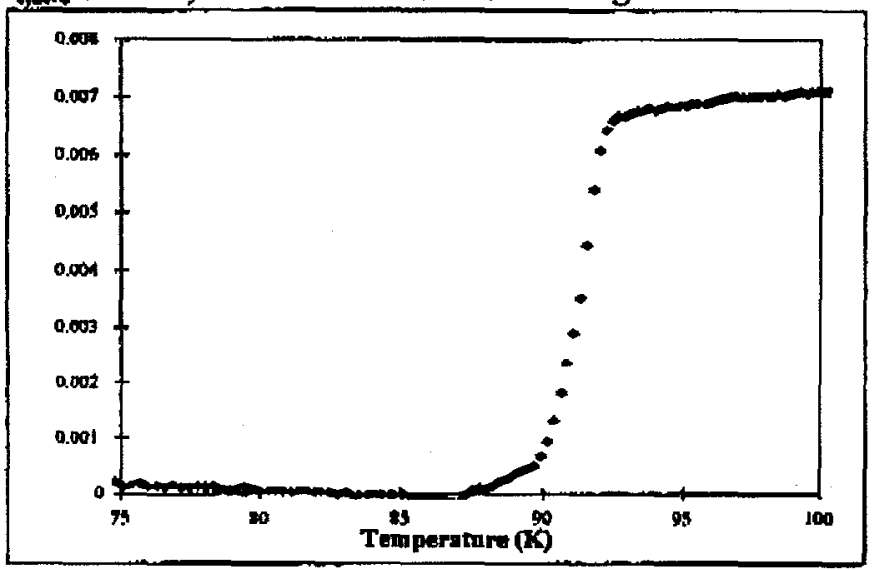

Flg. $7 T_{0}$ measurements from a YBCO film deposited by MOCVD on IBAD YSZ buffered metal substrate. A $T_{0}$ onset of $92 k$ and a $T_{\text {tremen }}$ of $87 \mathrm{~K}$ have been achitved.

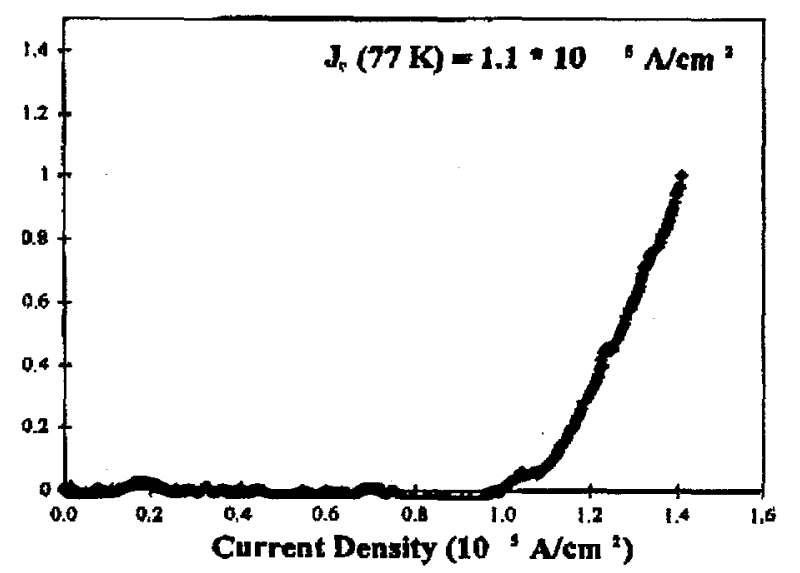

Fig. $8 \mathrm{~J}$, measurements on is YBCO film deposited by MOCVD on IBAD YSZ buffered metal substrate. A $t_{0}$ greater than $10^{9} \mathrm{~A} / \mathrm{cm}^{2}$ has been achteved.

meastrements were conducted on a film of size $1 \mathrm{~cm} \times 0.5$ $\mathrm{cm}$ and $0.5 \mu \mathrm{m}$ in thickness. $J_{c}$ measurement on one of the samples is shown in fig. 8. A $J_{0}$ of $1.1 \times 10^{5} \mathrm{~A} / \mathrm{cm}^{2}$ was achieved at $77 \mathrm{~K}$. The high $\mathrm{J}_{\mathrm{o}}$ achieved in a YBCO film on a metal substrate with a buffer layer that had a very broad texture and a very rough surface is encouraging.

\section{Conclusions}

YBCO films have been deposited by MOCVD on biaxially-texnured nickel substrates with an epitaxially grown $\mathrm{CeO}_{2}$ buffer layer as well as on nickel alloy substrates with biaxially-texcured YSZ buffer depositedby IBAD. A high degree of biaxial texture has been achieved in YBCO films on both types of substrates. A critical current density greater

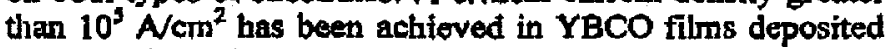
by MOCVD on buffered metal substrates.

\section{REFERENCES}

1. Y. Iijima $N$, Tanabe and $O$. Kohno, Atw, In Supereond, $I V$ ed. Hayakswa and Koshizulat Springer Veriag, Tokyo, (1992) pp. 679-682.

2. X. D. Wu, S. R. Foltyn, P. Arendt, J. Townsend, C. Adams, $t$. H. Campbell, P. Ttwarl, Y. Coulter, and D. E. Peterson, Appl, Phys. Letr. 65. (1994) pp. 1961-1963.

3. A. Goyal, D. P. Nonon, J. D. Budal, M. Paranthamna, E. D. Specht, D. M. Kroeger, D. K. Christen, O. He, B. Saffian, F. A. List, D. F. Lee, P. M. Martin, C. E. Kiabunde, E. Fatfield, and V. K. Silder, Appl. Phys. Letz 69, (1996) pp. $1795-1797$.

4. K. Hasegawe N, Yoshida, K. Fujiao, H. Mukai, K. Hayeshj, K. Sato, S. Honjo, Y. Sato. T. Ohkumn, H. Ishii, Y. Iwata, and T. Hart Proc. Ninth Im. Symp, Supercond Supporo, Japan, Oet 21-24, 1996.

5. V. Selvemanickam, A Ivenovg D. B. Fenner, T. Thurston, M. S. Walker, A. E. Kaloyenos, and P. Haldor, High Temperahurs Superconductors : Synthests, Processing, and Applications II, ed. U. Bulachondran and P. J. Mocinn, TMS Publication, Wursendale, (1996), pp. 165-174.

6. M. P. Chudzik, R. Enck, C. R. Kannewurf and M. T. Lanagan, "The deposition of biaxially textured ytria-stabilited zirconia by ion-beamassisted deposition", Proc. Appl. Supercond. Conf., Paim Desert, Ca., 1998. (to be published). 